\title{
Renoprotective and anti-oxidant effects of Coleus forskohlii against gentamicin induced nephrotoxicity in albino wistar rats
}

\author{
Nishat Fatima ${ }^{1 *}$, Ather Sultana ${ }^{1}$ \\ ${ }^{1}$ Shadan Womens College of Pharmacy, Department of Pharmacology, Hyderbad, India.
}

\begin{abstract}
The aim of present study was to evaluate the protective effects of Coleus forskohlii against Gentamicin (GM)-induced nephrotoxicity in male albino wistar rats.

Thirty rats were divided into five groups $(n=6)$. Control rats received normal saline. Nephrotoxicity was induced in rats by gentamicin $(8 \mathrm{omg} / \mathrm{Kg}$, IP) and treated with Silymarin (100mg/Kg, p.o,), aqueous and ethanolic extracts of (500mg/Kg, p.o) C. Forskohlii respectively for 15days. Markers of renal function (urea, uric acid and Creatinine), antioxidant markers were evaluated along with histopathological investigation in all experimental groups.

GM-treated rats showed significant increase in serum levels of renal markers, TBARS and decrease in GSH, SOD, CAT. Histopathological examinations of GMtreated rats revealed degenerative changes in glomeruli and renal tubules. Administration of aqueous and ethanolic root extracts of Coleus forskohlii, protected the kidney tissues against toxic effects of gentamicin as evidenced by amelioration of histopathological changes and normalization of kidney biochemical parameters.

The results of present study confirm the nephroprotective and anti-oxidant activity of C. forskohlii.
\end{abstract}

Key words: Coleus forskohlii, gentamicin, nephrotoxicity, antioxidant activity.

\section{INTRODUCTION}

Gentamicin is one of the widely used aminoglycoside antibiotics in treating gram negative bacterial infections. Its use is limited due to ototoxicity and nephrotoxic effects. It has been shown that up to $20 \%$ of people receiving gentamicin treatment develop symptoms of nephrotoxicity. Aminoglycosides throughout the

*Corresponding author: Dr. Nishat Fatima, e-mail: nishat_fatima50004@yahoo.com (Received 11 February 2018, accepted 18 March 2018 
endocytic pathway are taken up into the epithelial cells of the renal proximal tubules and stay there for a long time, which leads to nephrotoxicity. Acidic phospholipids, broadly distributed in the plasma membranes in various tissues, are considered to be the binding site of aminoglycosides in brush-border membrane of proximal tubular cell., ${ }^{1,2}$ Although the actual mechanism behind gentamicin induced nephrotoxicity is not clearly known, numerous studies have found involvement of different pathways, which includes, production of reactive oxygen species (ROS), reactive nitrogen species (RNS), and reduction in antioxidant defence. Activation of inflammatory processes, contraction of mesengial cells causing tubular necrosis and reduced glomerular filtration rates (GFR) are the other complications of chronic gentamicin administration.

Hydroxyl radicals play a vital role in the pathogenesis of gentamicin-induced nephrotoxicity, leading to suppression of $\mathrm{Na}(+)-\mathrm{K}(+)$-ATPase activity and DNA synthesis in rats proximal tubules causing renal injury. This injury may be relevant to reactive oxygen metabolites generated by gentamicin. Renal cortical mitochondria is the source of reactive oxygen metabolites, which induces renal damage. ${ }^{3}$

Plants produce large range of bioactive principles and constitutes a huge source of medicines. ${ }^{4,5}$ Being less expensive than synthetic drugs, herbal medicines are primarily used for treating mild or chronic ailments. In India 45,000 plant species have been identified and out of which 15-20 thousand plants are of good medicinal value. It is generally estimated that over 6000 traditional plants in India are in use as folk and herbal medicine, representing about $75 \%$ of the medicinal needs of the Third World countries. ${ }^{4}$ Literature suggests the use of compounds with antioxidant and anti-inflammatory properties and are capable of altering gentamicin-induced nephrotoxicity. ${ }^{3}$

Coleus forskohlii (CF) (Syn. Plectranthus Barbitus) is a medicinal plant belonging to family, Lamiaceae, with well-known efficacy in Ayurveda and Indian indigenous system of medicine. Different parts of the plant are documented in the treatment of various ailments such as heart diseases, respiratory disorders, asthma, bronchitis, constipation and epilepsy. Forskolin, is reported to be main active ingredient, which is a diterpene compound (7 $\beta$-acetoxy-8, 13-epoxy- 1a , $6 \beta$, 9 a-trihydroxy-labd-14-ene-11-one). ${ }^{6}$ Schaneberg et al., has successfully evaluated forskolin qualitatively and quantitatively from root and stem by using reversed-phase liquid chromatography. ${ }^{7}$ The roots are also useful in the treatment of worms, eczema and to alleviate burning in festering boils. ${ }^{8,9}$ However, so far, no scientific validity has been made to establish it as a nephroprotective agent. Hence, in the present study, an effort has been made to au- 
thenticate its traditional use by using ethanolic and aqueous root extracts of $\mathrm{CF}$ against gentamicin-induced nephrotoxicity in albino wistar rats.

\section{METHODOLOGY}

Authentication of plant material

The plant under study was identified and authenticated by the botanist, Dr. K. Madhav Chetty department of Botany in Sri Venkateshwara University, Tirupati, A.P, India and a specimen (voucher No.1965) has been deposited.

\section{Preparation of plant extracts:}

The dried roots of Coleus forskohlii were subjected to soxhlet extraction using ethanol as the solvent. Aqueous extract was prepared by freshly boiling in water before dosing.

\section{Preliminary phytochemical investigations}

The preliminary phytochemical investigations were carried out with ethanolic and aqueous extracts of dried roots of Coleus forskohlii for qualitative identification of phytochemical constituents present with each extract. Tests were carried out by standard methods described in practical Pharmacognosy by K.R. Khandelwal and Dr. C.K. Kokate..$^{10}$ All the chemicals and reagents used were of analytical grade.

\section{Experimental Animals}

The study protocol was approved by the Institutional Animals Ethics Committee (IAEC) of Committee for the purpose of Control and Supervision of Experiments on Animals (CPCSEA), Government of India, through its reference no. IAEC -01/SES/2017/101, Dated: 06/05/2017. Male and female wistar albino rats weighing 150-180 grams, were obtained from the animal house of Sainath Agencies, Hyderabad (282/PO/Bt/S/200o CPCSEA). The animals were housed with free access to food and water for one week in an air-conditioned room $\left(25^{\circ} \mathrm{C}\right)$ under a $12 \mathrm{hr}$ light: dark cycle prior to the experiment. During the experimental study rats were fed with pellets obtained from (Pranav Agro Industries limited, rat feed, India). The rats received humane care according to the criteria outlined in CPCSEA guidelines 2003, Government of India.

\section{Chemicals}

a. Silymarin - 100mg/Kg

Silymarin Tablets - Silybon 140mg, Micro labs Pvt Ltd.

Solan, Himachal Pradesh, India, Batch no. SIBDOO51,

MFD Jan 2017, Expiry date DEC 2018. 


\section{b. Gentamicin - 80mg/Kg}

Gentamicin Injection - Gentamicin Sulphate B.P,

$80 \mathrm{mg}$ in 2ml, Pfizer Laboratories Pvt Ltd.

Acute oral toxicity study

The acute toxicity studies for ethanolic and aqueous extracts of dried roots of Coleus forskohlii were done according to the OECD guidelines No. 423 using female albino wistar rats. ${ }^{11}$ Each animal was administered with the ethanolic and aqueous extracts of the plant by oral route $(2000 \mathrm{mg} / \mathrm{Kg}$ was used as starting dose). Animals were observed individually after dosing atleast once during the first 30 minutes. At regular intervals, they were observed during the first 24 hours, with special attention to the first four hours and thereafter daily for the next fourteen days.

\section{Evaluation of Nephroprotective Activity}

Male wistar albino rats were divided into five groups of six animals each. Group I Normal control rats were treated with isotonic saline; Group II, rats received gentamicin half an hour before administration of standard drug Silymarin 100 $\mathrm{mg} / \mathrm{Kg}$ in distilled water p.o; Group III, rats received only Gentamicin 8omg/ $\mathrm{Kg}$ in isotonic saline by intraperitoneal route, Group IV and V rats received gentamicin half an hour before administration of ethanolic and aqueous extracts of Coleus forskohlii (500mg/Kg) in aqueous solution respectively. 


\section{Grouping of Animals}

Table 1. Grouping of animals.

\begin{tabular}{|c|c|}
\hline Group & Treatment \\
\hline I-Normal Control & Normal Saline $0.5 \mathrm{ml} \mathrm{p.0}$ \\
\hline II- Standard & $\begin{array}{r}\text { Half an hour before administration of Silymarin } 100 \mathrm{mg} / \mathrm{Kg} \text { orally, } \\
\text { rats were injected with Gentamicin } 80 \mathrm{mg} / \mathrm{Kg} \mathrm{IP.}\end{array}$ \\
\hline III-Gentamicin Control & $\begin{array}{r}\text { Rats received only Gentamicin } 80 \mathrm{mg} / \mathrm{Kg} \text { in isotonic saline by } \\
\text { intraperitoneal route (IP). }\end{array}$ \\
\hline IV -Ethanolic extract & $\begin{array}{r}\text { Rats received gentamicin } 80 \mathrm{mg} / \mathrm{Kg}, \mathrm{IP} \text { half an hour before } \\
\text { administration of ethanolic extracts of Coleus forskohlii (500 } \\
\mathrm{mg} / \mathrm{Kg}), \mathrm{p} .0 .\end{array}$ \\
\hline V- Aqueous extract & $\begin{array}{r}\text { Rats received gentamicin } 80 \mathrm{mg} / \mathrm{Kg}, \text { IP half an hour before } \\
\text { administration of aqueous extracts of Coleus forskohlii (500 } \\
\mathrm{mg} / \mathrm{Kg}), \mathrm{p} .0 .\end{array}$ \\
\hline
\end{tabular}

The same dosing schedule was continued as per the assigned groups for 15 days for studying the gentamicin-induced nephrotoxicity. ${ }^{12,13}$

\section{Blood sampling}

At the end of experimental period (15 days) and after overnight fasting, blood samples were collected by retro-orbital puncture using capillary tube and animals were sacrificed using anaesthesia and kidneys were collected. Blood samples were centrifuged for 10 minutes at 3000 rpm within an hour and the sera were obtained.

Determination of serum urea, creatinine, uric acid and histopathology of kidney tissues

The serum parameters were estimated using standard kits obtained from Span Diagnostics, India and analysed spectrophotometrically by using double beam UV Visible spectro-photometer (UV-Visible spectrophotometer). Kidneys from all five groups were fixed in 10\% neutral buffered formalin and processed to paraffin wax. 5 microns Sections are stained with Haematoxyllin and Eosin, Massons trichrome, and Periodic Acid Schiff and are examined under light microscope at 100 and 400 magnifications. 


\section{Preparation of renal homogenate and determination of antioxidant markers}

The kidneys were removed and dissected free from the surrounding fat and connective tissue. Each kidney was longitudinally sectioned, and renal cortex was separated and kept at $-8^{\circ} \mathrm{C}$. Subsequently, renal cortex was homogenized in cold potassium phosphate buffer (0.05 M, pH 7.4). The renal cortical homogenates were centrifuged at $5000 \mathrm{rpm}$ for $10 \mathrm{~min}$ at $4^{\circ} \mathrm{C}$. The resulting supernatant was used for the determination of superoxide dismutase (SOD), ${ }^{14}$ catalase (CAT), ${ }^{15}$ lipid peroxidation (TBARS) ${ }^{16}$ and glutathione (GSH) ${ }^{17}$ using colorimetric assay.

\section{Statistical analysis}

Data was analysed by applying one-way ANOVA followed by Tukey's multiple comparison test using Graphpad Prism 5 software, version 5.3 La Jolla, San Diego, California, USA. Significance level was set at $\mathrm{p}<0.05$. All values are expressed as Mean \pm SEM.

\section{RESULTS}

\section{Preliminary phytochemical screening}

The preliminary phytochemical investigations of ethanolic and aqueous extracts of dried roots of Coleus forskohlii showed the presence of carbohydrates, proteins, amino acids, terpenoids and steroids, flavonoids, tannins, saponins and glycosides. Percentage yield of ethanolic extract was.11.35 grams and aqueous being 14 grams.

\section{Acute oral toxicity study}

Acute oral toxicity studies revealed the non-toxic nature of ethanolic and aqueous extracts of dried roots of Coleus forskohlii. There was no lethality observed nor any profound toxic reactions found at a dose of $2000 \mathrm{mg} / \mathrm{Kg}$ p.o. which pronounces the safety profile of the plant extract. Therefore $500 \mathrm{mg} / \mathrm{Kg}$ was selected for further study. 


\section{Gentamicin-induced nephrotoxicity study}

The results demonstrated significant improvement in urea, uric acid and creatinine levels on treatment with Silymarin, ethanolic and aqueous extracts of dried roots of Coleus forskohlii respectively, as these renal markers were increased in animals treated with gentamicin alone indicating nephrotoxicity. When compared between the two extracts, aqueous extracts have produced more potent reduction in the renal function parameters compared to the ethanolic extract treated group. Results are tabulated in (Table 2). Mean percent decrease in renal markers compared to gentamicin control are depicted in Figure 1,2, and 3.

Table 2. Effect of treatments on Serum Urea, Uric acid and Creatinine.

\begin{tabular}{|l|l|l|l|}
\hline Treatment Groups & Urea(mg/dl) & Uric acid(mg/dl) & Creatinine(mg/dl) \\
\hline Normal Control, Saline 0.5ml p.0 & $22 \pm 1.97$ & $2.7 \pm 0.07$ & $0.46 \pm 0.07$ \\
\hline Silymarin100mg/Kg, p.o & $28 \pm 1.16^{\mathrm{a}}$ & $3.1 \pm 0.18^{\mathrm{a}}$ & $0.5 \pm 0.08^{\mathrm{a}}$ \\
\hline Gentamicin Control $80 \mathrm{mg} / \mathrm{Kg}, \mathrm{IP}$ & $45 \pm 1.58^{\mathrm{b}}$ & $6.7 \pm 0.4^{\mathrm{b}}$ & $1.7 \pm 0.09^{\mathrm{b}}$ \\
\hline Aqueous Extract (CF) $500 \mathrm{mg} / \mathrm{Kg}$, p.0 & $29 \pm 1.71^{\mathrm{a}}$ & $3.4 \pm 0.2^{\mathrm{a}}$ & $0.6 \pm 0.06^{\mathrm{a}}$ \\
\hline Ethanolic Extract (CF) $500 \mathrm{mg} / \mathrm{Kg}$, p.0 & $34 \pm 1.24^{\mathrm{a}}$ & $4.6 \pm 0.3^{\mathrm{a}}$ & $1.1 \pm 0.7^{\mathrm{a}}$ \\
\hline
\end{tabular}

All values are expressed as Mean \pm SEM, (CF): Coleus Forskohlii

$\mathrm{a}: \mathrm{p}<0.001$ Compared to Normal Control

b: $\mathrm{p}<0.001$ Compared to Gentamicin Control

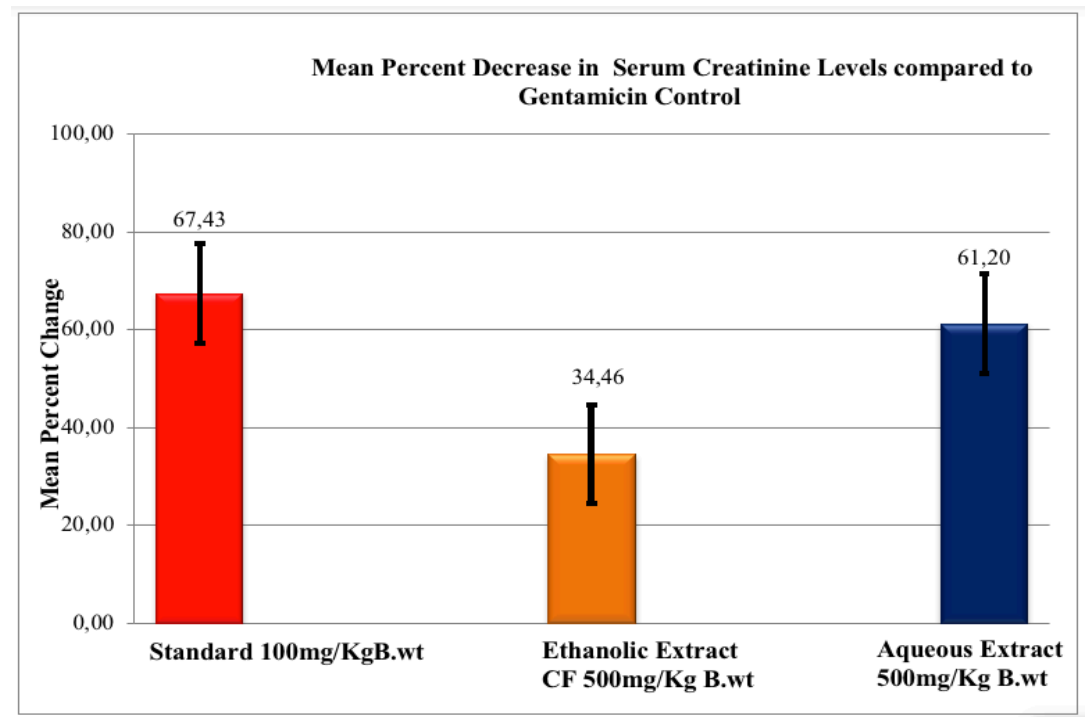

Figure 1. Mean percent decrease in serum creatinine levels compared to Gentamicin control. 


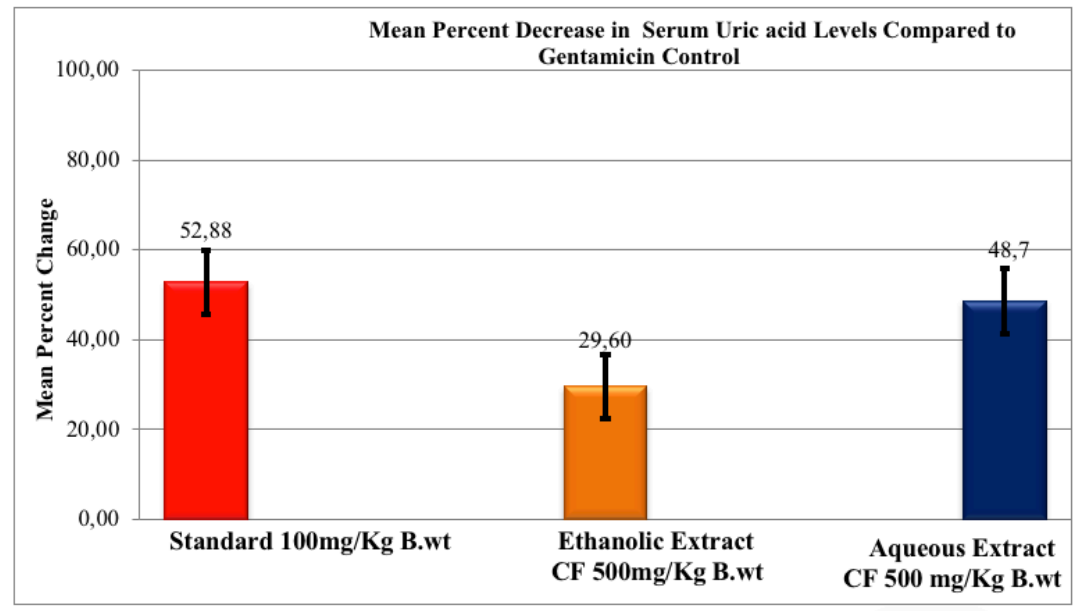

Figure 2. Mean percent decrease in serum uric acid levels compared to Gentamicin control.

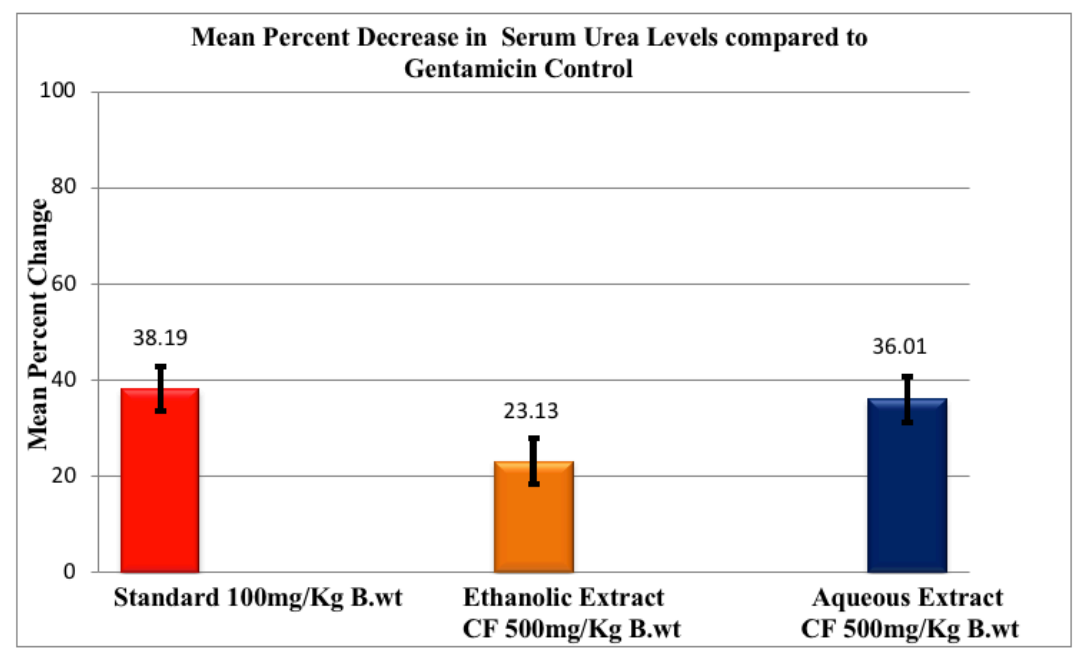

Figure 3. Mean percent decrease in serum urea levels compared to Gentamicin control. 


\section{Effect on body weights}

The body weights were decreased in gentamicin treated animals compared to their initial body weights. Treatment with Silymarin, ethanolic and aqueous extracts of Coleus forskohlii improved the body weights compared to gentamicin control group but not statistically significant. Comparison of initial and final body weight between the groups is depicted in (Table 3).

Table 3. Comparison between initial and final body weights.

\begin{tabular}{|l|l|l|}
\hline Treatment Groups & Initial Body Weight (grams) & $\begin{array}{l}\text { Final Body } \\
\text { Weight (grams) }\end{array}$ \\
\hline Normal Control, Saline $0.5 \mathrm{ml} \mathrm{p.0}$ & $180 \pm 0.9$ & $200 \pm 1.0$ \\
\hline Silymarin100mg/Kg, p.0 & $152 \pm 0.67$ & $166 \pm 2.44$ \\
\hline Gentamicin Control $80 \mathrm{mg} / \mathrm{Kg}, \mathrm{IP}$ & $166 \pm 1.47$ & $157 \pm 1.78$ \\
\hline Ethanolic Extract (CF) $500 \mathrm{mg} / \mathrm{Kg}$, p.0 & $156 \pm 1.21$ & $161 \pm 2.56$ \\
\hline Aqueous Extract(CF) $500 \mathrm{mg} / \mathrm{Kg}$, p.0 & $164 \pm 1.47$ & $170 \pm 2.33$ \\
\hline
\end{tabular}

All values are expressed as Mean \pm SEM, (CF): Coleus Forskohlii

\section{Effect on kidney weight:}

The kidney weights were increased in gentamicin treated groups compared to normal. Whereas treatment with Silymarin, ethanolic and aqueous extracts of Coleus forskohlii significantly reduced the relative kidney weights compared to the gentamicin control. Comparison of kidney weight between the groups is depicted in (Table 4).

Table 4. Effect treatments on kidney weight.

\begin{tabular}{|c|c|}
\hline Treatment Groups & Kidney Weight (grams) \\
\hline Normal Control Saline, $0.5 \mathrm{ml} \mathrm{p.0}$ & $0.66 \pm 0.01$ \\
\hline Silymarin100mg/Kg, p.o & $0.74 \pm 0.01$ \\
\hline Gentamicin Control $80 \mathrm{mg} / \mathrm{Kg}, \mathrm{IP}$ & $0.86 \pm 0.08$ \\
\hline Aqueous Extract (CF) $500 \mathrm{mg} / \mathrm{Kg}$, p.o & $0.65 \pm 0.09^{\mathrm{a}}$ \\
\hline Ethanolic Extract (CF) $500 \mathrm{mg} / \mathrm{Kg}, \mathrm{p} .0$ & $0.76 \pm 0.08^{\mathrm{a}}$ \\
\hline
\end{tabular}

All values are expressed as Mean \pm SEM, (CF): Coleus Forskohlii a: $\mathrm{p}<0.001$ Compared to Gentamicin Control 


\section{Results of Histopathology}

\section{Group I- Treated with normal saline}

The animals of Group I, were treated with only normal saline showed normal renal glomeruli with the intact bowman's capsule. Other structures like brush border cuboidal epithelium which lines the proximal convoluted tubules, simple cuboidal epithelium, which lines the distal convoluted tubules, and macula densa were very prominent. (Figure 4).

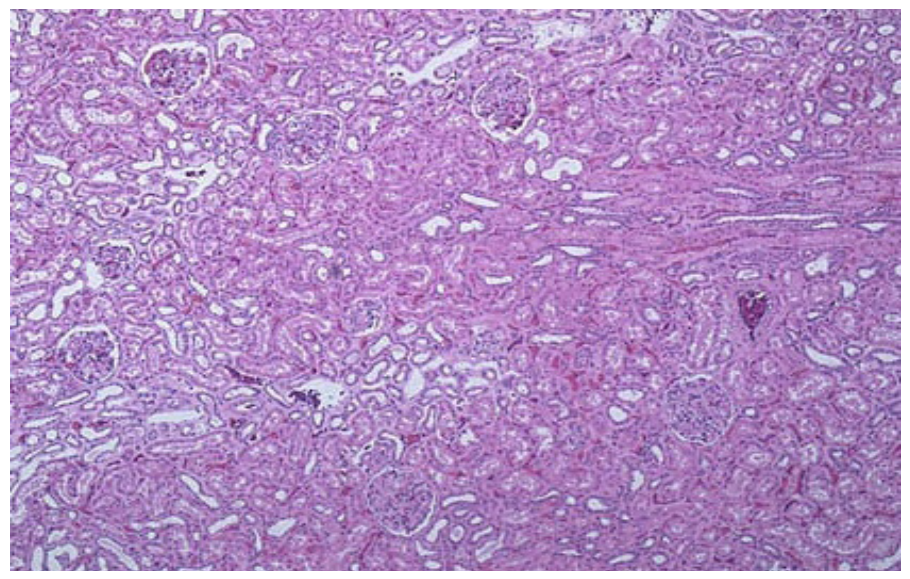

Figure 4. Photomicrograph of kidney of animals treated with normal saline.

\section{Group II- Treated with Gentamicin+ Silymarin}

Multifocal tubular inflammation in which infiltration of inflammatory cells are noticed. Glomerulus appeared normal, no degeneration nor inflammation was found. Only Moderate tubular degeneration was observed (Figure 5).

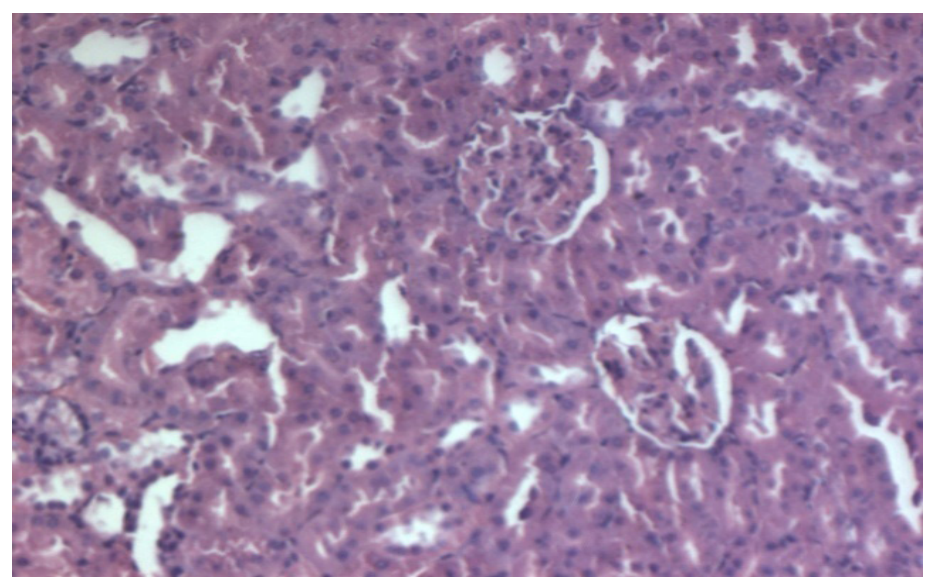

Figure 5. Photomicrograph of kidney of animals treated with Silymarin. 


\section{Group III- Treated with Gentamicin}

Close examination of the sections at high magnification, revealed the appearance of cells with alterations typical of apoptosis (cell shrinkage and cytoplasm eosinophilia, presence of small and shrunken nucleus with chromatin condensation), break down of glomerular capillaries and vacuolar appearance in tubular lumen, glomerular congestion, disruption of glomerular capillaries, vacuolar degeneration of tubular epithelial cell is observed with hyaline cast formation. Atrophic glomeruli are present effecting half of the cortical region. (Figure 6).

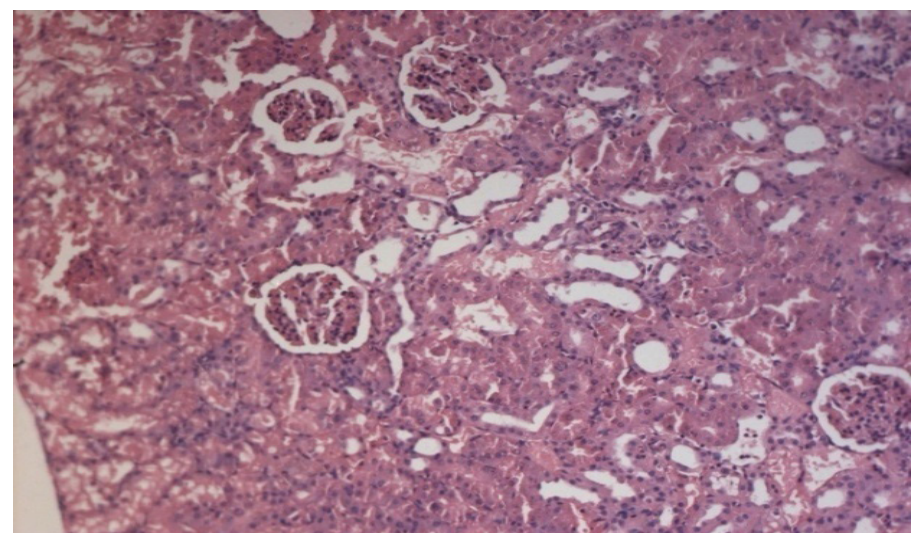

Figure 6. Photomicrograph of kidney of animals treated with Gentamicin

\section{Group IV- Treated with ethanolic extract of Coleus forskohlii + Gentamicin}

Treatment with Ethanolic extract of Coleus forskohlii reversed most of the histopathological alterations induced by Gentamicin as seen from the sections from gentamicin treated rats. Moderate tubular interstitial nephritis in which inflammation along with infiltration of inflammatory cells noticed in the interstitium between tubular region. Moderate tubular degeneration was also observed. (Figure 7).

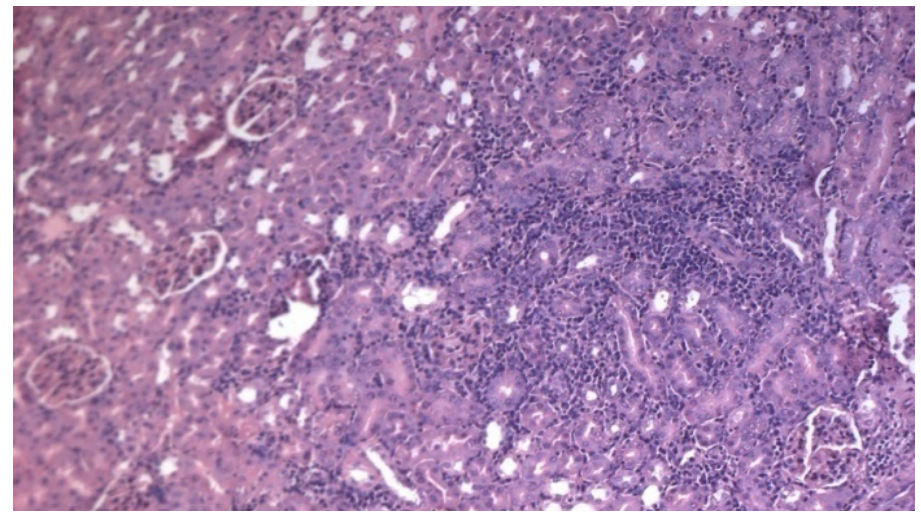

Figure 7. Photomicrographs of kidney of animals treated with ethanolic extract of $\mathrm{C}$. forskohlii and Gentamicin. 


\section{Group V-Treated with aqueous extract of C. forskohlii + Gentamicin}

Treatment with Ethanolic extract of Coleus forskohlii also reversed most of the histopathological alterations induced by Gentamicin. Photomicrographs of kidneys from this group revealed more prominent protection by showing normal glomeruli with absence of atrophy and hypertrophy. (Figure 8).

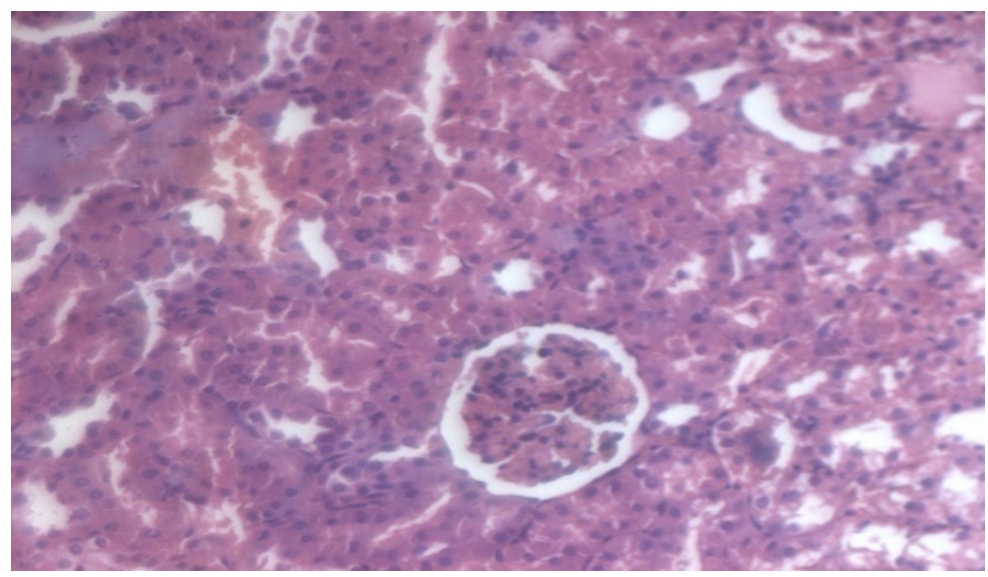

Figure 8. Kidney T.S. of animals treated with aqueous extract of $C$. forskohlii and Gentamicin.

\section{Effect of treatments on antioxidant enzymes.}

Treatment with gentamicin produced reduction in the superoxide dismutase levels compared to control. Whereas treatment with standard and extracts of $C$. forskohlii showed significant increase in superoxide dismutase levels compared to control indicating the antioxidant activity.

There was increase in malondialdehyde levels in gentamicin treated group compared to control, which suggests the nephrotoxic effect of gentamicin. However, two weeks of treatment with standard Silymarin and C. forskohlii showed significant decrease in thiobarbituric acid reactive substances i.e, malondialdehyde compared to control.

Treatment with standard, ethanolic and aqueous extract of $C$. forskohlii showed significant antioxidant effect, by producing increase in catalase levels compared to control. Gentamicin produced significant decrease in catalase levels compared to control, which explains the nephrotoxic effect of it.

Treatment with gentamicin showed significant decrease in glutathione levels, whereas two weeks of administration with Silymarin, ethanolic and aqueous extract of $C$. forskohlii produced significant increase in these levels compared to control. Results are shown in Table 5 . 
Table 5. Effect of treatments on antioxidant enzymes.

\begin{tabular}{|c|c|c|c|c|}
\hline Treatment Groups & $\begin{array}{c}\text { SODs (Units/ } \\
\text { mg protein) }\end{array}$ & $\begin{array}{c}\text { MDA } \\
\text { (nanomoles/g } \\
\text { tissue) }\end{array}$ & $\begin{array}{c}\text { Catalase (Units/ } \\
\text { mg protein) }\end{array}$ & $\begin{array}{c}\text { Glutathione } \\
\text { (Micromoles/g } \\
\text { tissue) }\end{array}$ \\
\hline $\begin{array}{c}\text { Normal Control } \\
\text { Saline, } 0.5 \mathrm{ml} p .0\end{array}$ & $16.01 \pm 0.46$ & $10.37 \pm 0.36$ & $15.20 \pm 0.42$ & $14.27 \pm 0.42$ \\
\hline $\begin{array}{c}\text { Silymarin100mg/ } \\
\text { Kg, p.0 }\end{array}$ & $16.93 \pm 0.31^{\mathrm{b}}$ & $8.49 \pm 0.33^{\mathrm{ab}}$ & $17.11 \pm 0.39^{\mathrm{ab}}$ & $16.26 \pm 0.35^{\mathrm{ab}}$ \\
\hline $\begin{array}{c}\text { Gentamicin } \\
\text { Control } 80 \mathrm{mg} / \\
\text { Kg, IP }\end{array}$ & $8.88 \pm 0.30^{\mathrm{a}}$ & $17.42 \pm 0.42^{\mathrm{a}}$ & $6.93 \pm 0.57^{\mathrm{b}}$ & $8.70 \pm 0.33^{\mathrm{b}}$ \\
\hline $\begin{array}{c}\text { Ethanolic Extract } \\
\text { (CF) } 500 \mathrm{mg} / \\
\text { Kg, p.0 }\end{array}$ & $11.14 \pm 0.58^{\mathrm{b}}$ & $14.02 \pm 0.30^{\mathrm{ab}}$ & $10.78 \pm 0.43 \mathrm{~b}$ & $10.89 \pm 0.50^{\mathrm{ab}}$ \\
\hline $\begin{array}{c}\text { Aqueous Extract } \\
\text { (CF) } 500 \mathrm{mg} / \\
\text { Kg, p.0 }\end{array}$ & $15.55 \pm 0.39^{\mathrm{b}}$ & $11.90 \pm 0.32^{\mathrm{b}}$ & $13.19 \pm 0.41^{\mathrm{b}}$ & $12.20 \pm 0.61^{\mathrm{ab}}$ \\
\hline
\end{tabular}

All Values expressed as Mean \pm SEM, (CF): Colueus Forskohlii

SOD: Superoxide dismutase, MDA: Malondialdehyde

a: $\mathrm{p}<0.001$ Compared to Normal Control

b: $\mathrm{p}<0.001$ Compared to Gentamicin Control

\section{DISCUSSION}

Gentamicin is a promising bactericidal with less bacterial resistance properties. It is known for producing reversible and irreversible renal toxicity. ${ }^{18}$ The key pathological event in gentamicin-induced nephrotoxicity is through accumulation of drug and eventually resulting in renal dysfunction. ${ }^{19}$ It is a cation, which has a strong affinity towards negatively charged brush-border membrane components of proximal tubule where it can form drug receptor complex with megalin, a cationic drug receptor. The specificity of renal toxicity is apparently related to its preferential accumulation in the renal proximal convoluted tubules (50 to 100 times greater than serum). Then, pinocytosis translocates the drug to lysosomes, where phospholipidosis takes place to interrupt various intracellular renal functions leading to renal injury. ${ }^{20,21}$ This renal injury in turn manifests the migration of monocytes and macrophages to the site of injury by stimulating intercellular adhesion molecule-1 and monocyte chemoattractant protein..$^{22,23}$ Kacew et al. and Aronoff et al., ${ }^{24-27}$ demonstrated that the accumulation of the drug in specific target organelles in the renal cortex may be the critical step in 
nephrotoxicity and it is generally agreed that gentamicin produces dose-dependent proximal renal tubular necrosis, which can be dissociated from intracellular accumulation. Papanikolaou et al, ${ }^{28}$ reported that gentamicin is incorporated and accumulated in proximal tubule lysosomes which explain the gentamicininduced nephrotoxicity.

GM induced nephrotoxicity is distinguished by elevated levels of urea and creatinine in plasma as well as urine, along with severe proximal tubular necrosis, resulting renal failure. ${ }^{29}$ Similarly it is reported that treatment with only GM leads to significant increase in weight of kidney in rats. ${ }^{30}$ Several days of treatment with aminoglycosides can cause defect in renal concentrating ability, which leads to mild proteinuria, reduction in glomerular filtration rate and appearance of hyaline and granular casts. Padmini et al, in their study reported that administration of $80 \mathrm{mg} / \mathrm{Kg}$ gentamicin dose in rats for ten days produced significant increase in serum creatinine, urea and uric acid. ${ }^{31}$ Similar pattern of changes were also observed in our study following GM treatment. Supplementation with aqueous and ethanolic extracts of roots of $C$. forskohlii in GM treated rats recorded decrement in levels of urea, uric acid and creatinine in serum which explains the worthwhile effect of this plant product on renal function. These observations indicate an improved renal function in form of effective clearance of urea and creatinine. Silymarin was also found to reduce the levels of renal markers similar to the plant extracts used in the study.

The release of oxygen-free radicals has been proposed as important mediator of GM-induced acute renal failure. ${ }^{32}$ These reactive oxygen species (ROS), lead to deficiency in intrinsic antioxidant enzymes. ${ }^{33-36}$ Its administration into rats induced impairment of renal function through liberation of oxygen free radical. ${ }^{35}$ ROS have been suggested as a cause of death for many cells in different pathological states including various models of renal and cardiac diseases. ${ }^{37} \mathrm{Sev}-$ eral compounds with antioxidant activity has been successfully used to prevent or ameliorate gentamicin-induced nephrotoxicity. In the present study, the role of ROS in GM-induced nephrotoxicity was assessed by employing antioxidant agent, $C$. forskohlii, and further evaluation of alterations in the biochemical indicators of oxidative stress mainly GSH, TBARS levels, SOD and CAT.

It has been reported that under normal conditions, ROS, which are generated during cellular functions, are eliminated by intrinsic antioxidant enzymes like superoxide dismutase, catalase and glutathione peroxidase. Therefore, ROS scavengers and antioxidant molecules have the capacity to partially reduce or eliminate the deleterious effects induced by gentamicin. In the present study, the levels of lipid peroxidation stress markers significantly increased in GM 
treated animals. Whereas treatment with $C$. forskohlii, demonstrated significant decrease in TBARS, indicating its anti-oxidant effect. Our study results are in accordance with the earlier published reports which explains the beneficial effect of $C$. forskohlii against reactive oxygen species.

Medicinal plants are important sources of natural products which differ widely in terms of their structures, biological properties and mechanisms of action. Various phytochemical components, especially polyphenols such as tannins, flavonoids, phenyl propanoids and phenolic acids, are known to be have antioxidant and free radical scavenging efficacy. Polyphenols have various biological effects, which are mainly attributed to their antioxidant activities in scavenging free radicals, inhibition of lipid peroxidation and metal chelation. Polyphenols share the same general chemical pattern, with one or more phenolic groups which react as hydrogen donors and thus neutralize free radicals. The protective effect of this plant against gentamicin-induced nephrotoxicity can be attributed to the presence of phytoconstituents such as flavonoids, terpenoids and phenols. Forskolin being the major chemical constituent, herbal preparations of it act on various multiple pharmacological mechanisms. Forskolin was identified in shoot differentiating culture, micropropagated plants and root organ suspension by TLC and HPLC. ${ }^{38}$ The blood pressure lowering and antispasmodic effects of extracts of $C$. forskohlii roots were reported by Dubey et al, based on the extensive screening of Indian plants for biological activity. ${ }^{39}$ The principle mechanism by which forskolin exerts its hypotensive activity is by stimulation of adenylate cyclase and thereby increasing cellular concentrations of the secondary messenger cyclic AMP (cAMP). ${ }^{40}$

Some investigators have demonstrated in their observations regarding the histopathological and structural changes in renal tissue post administration of GM.41,42 In our earlier study,we have reported the histopathological view of renal sections in GM treated group which showed degeneration, desquamation and necrosis in tubules and swelling in glomerulus, as compared to control group. ${ }^{13}$ Similarly, in the present work on histopathological examination we have observed damage in the structure of kidneys of gentamicin treated rats. Glomerular and tubular epithelial changes were considerably mild in the groups treated with aqueous and ethanolic extract of $C$. forskohlii along with restoration of normal histopathology. Two weeks of treatment with GM+ethanolic extract in the dose of 500mg/Kg showed moderate tubular epithelial changes while in case of animals treated with GM+aqueous showed regeneration in tubular epithelial cells. We expect that, morphological changes in kidneys were because of GM injection, but these changes were considerably mild in GM plus aqueous extract treatment. In summary, our data indicate that GM-induced nephrotoxicity might be related 
to oxidative damage. Co-administration of $C$. forskohlii diminished the negative effects of GM-induced nephrotoxicity possibly by inhibiting free radical mediated process. Further investigation of these promising protective effects of $C$. forskohlii against GM-induced renal injury may have a considerable impact on developing clinically feasible strategies to treat patients with renal failure.

\section{CONCLUSIONS}

In conclusion, the results of the present study infer that the antioxidant activity and medicinal properties of $C$. forskohlii may be responsible for protection against GM-induced renal damage. When compared between the two extracts, aqueous extract showed more potent response in comparison to ethanolic. These findings also suggest the probable efficacy of $C$. forskohlii extract against oxidative deterioration and can be useful novel nephroprotective agent in the prevention of oxidative stress-related degenerative diseases. Further studies are warranted in pre-clinical and clinical set up, and for studying the structure of phytoconstituents in establishing pharmacological activities.

\section{ACKNOWLEDGEMENTS}

The authors thank Shadan Educational Society, Hyderabad, India, for providing necessary facilities for carrying out this research study. The authors are also thankful to Mr. M.A. Hafeeze Khan for assisting in study related procedures.

Funding: No funding sources

Conflict of interest: None declared

\section{REFERENCES}

1. Nagai, J. Molecular mechanisms underlying renal accumulation of aminoglycoside antibiotics and mechanism-based approach for developing non-nephrotoxic aminoglycoside therapy. Yakugaku Zasshi. 2006, 126 (5), 327-35.

2. Abdel, Rahman.; R.S. Protective effect of apocynin against gentamicin induces nephrotoxicity in rats. Human \& Experimental Toxicology. 2017, 37(1), 27-37.

3. Mohammed, A.M.; Salwa I.A.; Entesar FA, Maha Y. K, Rehab A R, Magdy KH. Sildenafil Ameliorates Gentamicin-Induced Nephrotoxicity in Rats. Role of iNOS and eNOS. Journal of Toxicology. 2014, 4893, 82.

4. Zeynab, M. Y.; Najafi, H.; Hamid, S.M. Protective of crocin on gentamicin induced nephrotoxicity in rats. Iranian Journal of Basic Medical Sciences. 2016, 19(3) ,337-343.

5. Al, asbahi, R.H.; Melziq, M.F. Plectranthus barbatus: A Review of photochemistry. ethanobotanical uses and pharmacology-part 1. Planta Med. 2010, 76 (7), 653-61.

6. Kambham, V.N.; Devanna, K.B; Chandrasekhar. Preliminary phytochemical screening of roots of Coleus forskohlii. International Journal of Current Trends In Pharmaceutical Research. 2014, 2 (6), 703-708. 
7. Schaneberg, B.T.; Khan, I.A. Quantitative analysis of forskolin in Coleus forskohlii (Lamiaceae) by reversed-phase liquid chromatography. JAOAC Int. 2003, 86, 467-470.

8. Sharma, Y.; Vasundhara, M. Coleus (Plectranthus Barbatus) - A Multipurpose Medicinal Herb. International Research Journal of Pharmacy. 2011, 2 (3), 47-58.

9. Malarvizhi, A.; Sivangami, S. Antioxidant potential of roots of Coleus Forskohlii in Balc/C Mice with DLA tumour. International Journal of Pharmaceutical Sciences and Research. 2015, 31(1), 38-41.

10. Khandelwal, K.R.; Kokate, C.K.; Gokhale, S.R. Practical Pharmacognosy Techniques and Experiments. Pune: Nirali Prakashan Publications; 1996, 104-106.

11. OECD Guideline for Testing of Chemicals. Acute Oral Toxicity - Fixed Dose Procedure. 423 Adopted: 17th December; 2001.

12. Ramesh, K.; Sudha, A.; Manimaran, A.; Saravanan, D.; Natrajan, E. Beneficial Effect of Bacopa Monniera Extract on Gentamicin Induced Nephrotoxicity and Oxidative stress in Albino Rats. International Journal of Pharmacy and Pharmaceutical Sciences. 2011, 3(5), 144-148.

13. Nishat, F.; Hajera, S. Evaluation of protective effect of Terminalia Bellarica against gentamicin induced nephrotoxicity in albino rats. Pharmaceutical and Biological Evaluations. 2016, 3 (5), 486-494.

14. Caraway, W.T. Uric acid. In: Standard methods of clinical chemistry. Vol. 4. New York, 1963: 239 .

15. Habig, W.H.; Pabst, M.J.; Jakoby, W.B. Glutathione-S-transferase the first enzymatic step in mercapturic acid formation. $J$ Biol Chem. 1974, 249(7), 130-139.

16. Aebi, H. Catalase In: Methods in enzymatic analysis. Bergmeyer. H.U. (Eds.). Academic Press. New York; 1983, 276-286.

17. Rao, K.S.; Recknagel, R.O. Early onset of lipid peroxidation in rat liver after carbon tetrachloride administration. Exp Mol Pathol. 1968, 9, 271-278.

18. Appel, G.B. Aminoglycoside nephrotoxicity. Am J Med. 1990, 88,165-205.

19. Hori, R.; Inui, K. Cellular basis of aminoglycoside nephrotoxicity. Physiology. 1989, 4, $181-184$.

20. Laurent, G.; Carlier, M.B.; Rollman, B.; Van, Hoof. F.; Tulkens, P. Mechanism of aminoglycoside-induced lysosomal phospholipidosis: In vitro and in vivo studies with gentamicin and amikacin. Biochem Pharmacol. 1982, 31, 3861-3870.

21. Sandhu, J.S.; Sehgal, A.; Gupta, O.; Singh, A. Aminoglycoside nephrotoxicity revisited. $J$ Indian Acad Clin Med. 2007, 8, 331-333.

22. Wahl, S.M.; Hunt, D.A.; Wakefield, L.M.; McCartney-Francis, N.; Wahl, L.M.; Roberts. A.B.; et al. Transforming growth factor type beta induces monocyte chemotaxis and growth factor production. Proc Natl Acad Sci. 1987, 84, 5788-5792.

23. Feng, L.; Mathison, J.C.; Wilson, C.B. Cytokine expression, upregulation of intercellular adhesion molecule-1, and leukocyte infiltration in experimental tubulointerstitial nephritis. $L a b$ Invest. 1994, 70, 631-638.

24. Kacew, S.; Bergeron, M.G. Pathogenic factors in aminoglycoside-induced nephrotoxocity. Toxicol Letters. 1990, 51, 241-59.

25. Aronoff, G.R.; Pottratz, S.T.; Brier, M.E.; Walker, N.E.; Fineberg, N.S.; Glant, M.D.; Luft, 
F.C. Aminoglycosides accumulation kinetics in rat renal parenchyma. Antimicrob Agents Chemother. 1983, 23, 74-78.

26. Patel, V.; Luft, F.C.; Yum, M.N.; Patel, B.; Zeman, W.; Kleit, S.A. Enzymuria in gentamicin induced kidney damage. Antimicrobial Agents Chemotherapy. 1975, 7, 364-369.

27. Bennet, W.M; Elliott, W.C.; Houghton, D.C.; Gilbert, D.N.; Defehr, J.; McCarran, D.A. Reduction of experimental gentamicin nephrotoxicity in rats by dietary calcium loading. Antimicrob Agents. Chemother. 1982, 22, 508-512.

28. Papanikolaou, N.; Peros, G.P.; Morphake, P.; Gkikas, G.; Maraghianne, D.; Tsipas, G.; et al. Does gentamicin induce acute renal failure by increasing renal TX2 synthesis in rats. Prostaglandins. Leukotrienes and Essential Fatty Acids. 1992, 45, 131-136.

29. Laskshmi, B.V.S.; Sudhakar, M. Protective effect of Zingiber officinale on gentamicininduced nephrotoxicity in rats. Int $J$ Pharmacol. 2010, 6, 58-62.

30. Gilbert, D.N.; Wood, C.A.; Kohlhepp, S.; Kohnen, P.W; Houghton, D.C.; Finkbener, H.C.; et al. Polyaspartic acid prevents experimental aminoglycoside nephrotoxicity. J Infect Dis. 1989, 159, 945-53.

31. Padmini, P.M.; Kumar, V.J. A Histopathological Study on Gentamicin Induced Nephrotoxicity in Experimental Albino Rats. Journal of Dental and Medical Sciences. 2012, 1, 14-17.

32. Baliga, R.; Ueda, N.; Walker, P.D.; Shah, S.V. Oxidant mechanisms in toxic acute renal failure. Drug Metab Rev. 1999, 31, 971-997.

33. Morales, A.I.; Buitrago, J.M.; Santiago, J.M.; Fernández, T. M.; López-Novoa, J.M.; Pérez, B.F. Antioxid. Redox Signal. 2002, 4, 893-898.

34. Yanagida, C.; Ito, K.; Komiya, I.; Horie, T. Protective effect of fosfomycin on gentamicin- induced lipid peroxidation of rat renal tissue. Chem Biol Interact. 2004, 148, 139-147.

35. Maldonado, P.D.; Barrera, D.; Medina-Campos, O.N.; Hernández- Pando, R.; Ibarra-Rubio, M.E.; Pedrazza-Chaverri J. Aged garlic extract attenuates gentamicin induced renal damage and oxidative stress in rats. Life Sci. 2003, 73(20), 2543-2556.

36. Heibashy, M.I.A.; Abdel, Moneim A.E. Kidney and liver function tests after late Dimethyl sulfoxide (DMSO) administration in rats with gentamicin induced acute renal failure. $J$ Egypt Ger Soc Zool. 1999, 30, 35-48.

37. Pedraza, J.C.; Barrera, D.; Hernández, P.R.; Medina, O.N.; Cruz, C.F., Murguia, F.; et al. Soy protein diet ameliorates renal nitrotyrosine formation and chronic nephropathy induced by puromycin aminonucleoside. Life Sci. 2004, 74, 987-999.

38. Sen, J.; Sharma, A.K.; Sahu, N.P.; Mahato, S.B.; Production of forskohlin in in vitro cultures of Coleus forskohlii. Planta Med. 1992, 58, 324-332

39. Dubey, M.P.; Srimal RC, Patnaik GK, Dhawan BN. Blood pressure lowering and antispasmodic effects of C.forskohlii Briq. Indian J. Pharm. 1974, 6, 15 .

40. Seamon, K.B.; Daly, J.W. Forskolin: a unique diterpene activator of cyclic AMP-generating systems. J. Cyclic Nucleotide Res. 1981, 7, 204-224.

41. Soumya, P.S.; Poornima, K.; Ravikumar, G.; Kalaiselvi, M.; Gomathi, D.; Uma; C. Journal of Pharmacy Research. 2011, 4(8), 2474-2476.

42. Sodimbaku, V.; Pujari, L.; Mullangi, R.; Marri, S.Carrot (Daucus carota L.): Nephroprotective against gentamicin-induced nephrotoxicity in rats. Indian J Pharmacol. 2016, 48 (2), 122-127. 